\title{
The effects of Urtica dioica L. ethanolic extract against urinary calculi in rats
}

\author{
Rümeysa KELEŞ ${ }^{1}\left(\mathbb{D}\right.$, Ali ŞEN ${ }^{2}(\mathbb{D})$, Büşra ERTAŞ ${ }^{1}(\mathbb{D})$, Damla KAYALI ${ }^{3}(\mathbb{D})$, Pinar EKER $^{4}(\mathbb{D}$, \\ Tarık Emre ŞENER ${ }^{5}(\mathbb{D})$, Ahmet DOĞAN ${ }^{6} \mathbb{D}^{D}$, Şule ÇETINEL ${ }^{3}$ (D) , Göksel ŞENER ${ }^{1 *}$ (D)
}

1 Department of Pharmacology, Faculty of Pharmacy, Marmara University, Haydarpasa 34668 Istanbul, Turkey.

2 Department of Pharmacognosy, Faculty of Pharmacy, Marmara University, Istanbul, Turkey.

3 Department of Histology \& Embryology, Faculty of Medicine, Marmara University, Istanbul, Turkey.

4 Department of Biochemistry, Umraniye Research and Training Hospital, Istanbul, Turkey.

5 Department of Urology, Faculty of Medicine, Marmara University, Istanbul, Turkey.

6 Department of Pharmaceutical Botany, Faculty of Pharmacy, Marmara University.

* Corresponding Author. E-mail: gsener@marmara.edu.tr (G.Ş.); Tel. +00-90-216-414 2962.

Received: 05 December 2019 / Revised: 27 January 2020 / Accepted: 30 January 2020

\begin{abstract}
Nephrolithiasis is common urological problem and stone formation has multiple underlying pathogenetic factors. We investigated the possible preventive and therapeutic effects of Urtica dioica ethanol extract (UD) on ethylene glycol-induced nephrolithiasis model in rats. Sprague-Dawley rats were divided into four groups $(n=10)$. The control group was given normal drinking water for 8 weeks and was administered vehicle by gastric gavage. Stone formation was induced by adding $0.75 \%$ ethylene glycol (EG) to their drinking water. UD $(700 \mathrm{mg} / \mathrm{kg}$ ) was given orally for 8 weeks to the preventive group and for last 4 weeks to the treatment group, respectively. At the end of the experiment, urine, blood samples and kidney tissues were obtained. In 24-hour urine samples, calcium and citrate levels were decreased and oxalate levels were increased in EG group whereas UD treatment groups reversed these parameters back to control levels. In addition, serum levels of creatinine and urea were increased in EG group, while UD significantly reduced these parameters. Malondialdehyde, 8-hydroxydeoxyguanosine and tumor necrosis alpha levels, and caspase3 and N-acetyl- $\beta$-glucosaminidase activities were elevated in EG group and showed a decrease in UD treated groups. Glutathione level was decreased in EG group, whereas it was increased in UD preventive group. Histological examination showed an improvement in UD treated groups. Our results suggest that UD is effective both in prevention and treatment for kidney stones. The mechanism underlying this effect may be the antioxidant effect of UD and the effect on the concentration of stone-forming components in the urine.
\end{abstract}

KEYWORDS: Urtica dioica; kidney stone; calcium oxalate; urolithiasis; antioxidant.

\section{INTRODUCTION}

Nephrolithiasis is a worldwide condition affecting nearly $12 \%$ of the population [1]. Incidence is linked to geography, ethnicity, genetic, gender, dietary habits, lifestyle and various systemic diseases such as obesity, diabetes, cardiovascular diseases, metabolic syndrome [2,3]. The rate of recurrence is nearly $50 \%$ in 5 years and there is no radical treatment to prevent formation of stone in kidney [4]. Although there are many underlying mechanisms for stone formation, data suggest that oxidative stress is one of the major reasons for kidney stone formation. Stone formation is a complicated process resulting from multiple physicochemical events including supersaturation, crystal nucleation, growth, aggregation, and their retention in the kidneys. These processes are regulated by a variety of inorganic, organic promoters and urinary macromolecules, which form stones organic component or matrix [5]. Almost $80 \%$ of kidney stones consist of calcium oxalate (CaOx), whereas $5-10 \%$ are uric acid stones cystine, and struvite stones [6]. Renal cellular exposure to CaOx crystals cause oxidative stress (OS) by which reactive oxygen species (ROS) are formed, followed by cellular injury and inflammation. Accordingly, ROS are related to signaling molecules and factors of injury and inflammation during stone formation [7]. Renal tubular cell injury has a significant role in stone formation providing sites for crystal attachment to renal tubular cells and eventual retention within kidneys [1]. Medicinal plants having biological activity such as Camellia sinensis, Ammi visnaga and Nigella sativa have been reported as an effective therapeutic option for kidney stone disease. Generally, these therapeutic effects of plants are attribute to their

How to cite this article: Keleş R, Şen A, Ertaş B, Kayalı D, Eker P, Şener TE, Doğan A, Çetinel Ş, Şener G. The effects of Urtica dioica L. ethanolic extract against urinary calculi in rats. J Res Pharm. 2020; 24(2): 205-217. 
antioxidant contents [8]. Therefore, it is important to carry out research on medicinal plants as potential sources in new anti-nephrolithiasis effective drug discovery.

Urtica dioica L. (Urticaceae) is one of the five Urtica species known to grow in Turkey [9] and is used for various purposes in folk medicine. Traditionally, it has been used for complaints associated with nasal and menstrual haemorrhage, rheumatism, eczema, anaemia, nephritis, haematuria, jaundice, menorrhagia, diarrhea, osteoarthritis, urinary tract infections, rheumatoid arthritis, allergies, Alzheimer's, asthma, bladder problems, bronchitis, bursitis, gingivitis, gout, cough, hair growth, kidney stones, prostate enlargement, tendinitis, gastrointestinal tract, also as blood purifier, emmenagogue, diuretic [10,11,12]. Phytochemical studies have shown that the main constituents of Urtica dioica are flavonoids (kaempferol, isorhamnetin, quercetin, isoquercitrin, astragalin, and rutin), other phenolics ( phenylpropanes, caffeic acid, chlorogenic acid and scopoletin), tannins, essential oil (carvacrol, carvone, naphthalene, (E) - anethol, hexahydrofarnesyl acetone, (E) - geranyl acetone, (E) - $\beta$ - ionone phytol), fatty acids, polysaccharides, isolectins, sterols, terpenes, protein, vitamins (A, B1, B2, C, D, E, K) and minerals (calcium, chromium, cobalt, copper, iron, magnesium, phosphorus, potassium, silicon, sodium, sulfur, zinc) [10,11]. It has also been reported that various extracts obtained from Urtica dioica have significant antioxidant, antidiabetic, hepatoprotective, anti- hyperlipidemic, diuretic, antiviral, antimicrobial, cardiovascular, anti-inflammatory, analgesic, anti- arthritic, immunomodulatory, anticancer, hypotensive, and anthelmintic activities [10].

Considering these previous studies and knowledge, we decided to evaluate whether ethanol extract of Urtica dioica has preventive and/or therapeutic effects on ethylene glycol (EG) induced renal stone formation in rats.

\section{RESULTS}

\subsection{Antioxidant/anti-inflammatory activity and total phenolic content of UD}

UD with an $\mathrm{IC}_{50}$ value of $359 \pm 3.61 \mu \mathrm{g} / \mathrm{ml}$ showed moderate antioxidant activity when in comparison with the standard $\left(\mathrm{IC}_{50}\right.$ for Ascorbic acid: $\left.17.60 \pm 0.37 \mu \mathrm{g} / \mathrm{ml}\right)$ against DPPH radical. Also, UD with an $\mathrm{IC}_{50}$ value of $78.34 \pm 3.28 \mu \mathrm{g} / \mathrm{ml}$ exhibited good antioxidant activity when compared to the standard (IC 50 for Trolox: $17.22 \pm 0.00 \mu \mathrm{g} / \mathrm{ml}$ ) against ABTS radical. The UD exhibited good anti-inflammatory activity with an $\mathrm{IC}_{50}$ value of $140.30 \pm 5.02 \mu \mathrm{g} / \mathrm{ml}$ against 5-lipoxygenase enzyme (IC $\mathrm{I}_{50}$ for standard indomethacin: $22.39 \pm 0.26$ $\mu \mathrm{g} / \mathrm{ml}$ ). Finally, the total phenolic content of the UD was found to be $35.5 \pm 0.59 \mathrm{mg} / \mathrm{g}$ extract as gallic acid equivalent.

\subsection{Biochemical parameters in urine and serum}

At the end of the experimental period, no significant differences in body weight among the groups. As expected, 8 weeks EG administration resulted in hyperoxaluria. Table 1 demonstrates the effects of UD extract on urine biomarkers. Oxalate content in the EG group was increased significantly compared with the control group group $(\mathrm{p}<0.001)$. Treatment groups reduced these rises significantly. Preventive group $(\mathrm{p}<0.01)$ increased this level more than therapeutic group $(p<0.05)$. In urine, calcium and citrate levels of EG group were decreased significantly $(\mathrm{p}<0.05, \mathrm{p}<0.001$, respectively) while calcium levels in preventive and therapeutic UD groups were increased back to control group levels $(\mathrm{p}<0.05)$. In UD preventive and therapeutic groups, citrate levels were increased significantly ( $\mathrm{p}<0.05, \mathrm{p}<0.01$, respectively). There were no significant differences in phosphate levels between groups.

The contents of serum biomarkers are shown in Table 1. Creatinine and urea levels were significantly increased in EG group compared to the control group $(\mathrm{p}<0.001)$. Both treatment regimens with UD approached the creatinine and urea levels to the control values $(\mathrm{p}<0.001)$.

\subsection{Biochemical parameters in kidney tissue}

\subsubsection{Effect of UD treatments on Glutathione and Malondialdehyde levels}

Kidney tissue GSH levels in EG group were significantly lower $(p<0.001)$ than the control group. On the other hand, UD pretreatment seemed to be effective on the restore of GSH since there was significant $(p<0.05)$ increase (Figure 1). As a result of decrease in GSH levels, as expected the tissue MDA levels were significantly higher in EG group when compared to the control group $(p<0.001)$, while in the both regimen UD treatment suppressed this MDA levels significantly compared to the EG-treated group $(p<0.01)$. 
Table 1. Biochemical variables in urine and serum.

\begin{tabular}{lcccc}
\hline $\begin{array}{l}\text { Parameter } \\
\text { (units) }\end{array}$ & Control & EG & UD prevention & UD therapeutic \\
\hline Urine $/ 24 \mathbf{h}$ & & & & \\
\hline $\begin{array}{l}\text { Oxalate } \\
\text { (mmol/L) }\end{array}$ & $0.85 \pm 0.06$ & $2.64 \pm 0.34^{* * *}$ & $1.17 \pm 0.26^{++}$ & $1.53 \pm 0.26^{+}$ \\
$\begin{array}{l}\text { Calcium } \\
\text { (mmol/L) }\end{array}$ & $7.9 \pm 1.04$ & $4.54 \pm 0.45^{*}$ & $7.6 \pm 0.59^{+}$ & $7.5 \pm 0.79^{+}$ \\
$\begin{array}{l}\text { Citrate } \\
\text { (mmol/L) }\end{array}$ & $5.96 \pm 0.64$ & $2.54 \pm 0.17^{* * *}$ & $5.1 \pm 0.31^{++}$ & $4.56 \pm 0.48^{+}$ \\
Phosphate & $3.92 \pm 0.45$ & $4.26 \pm 0.49$ & $3.5 \pm 0.49$ & $3.72 \pm 0.23$ \\
\hline Serum & & & & \\
\hline $\begin{array}{l}\text { Creatinine } \\
\text { (mg/dl) }\end{array}$ & $0.46 \pm 0.03$ & $0.72 \pm 0.03^{* * *}$ & $0.52 \pm 0.01^{+++}$ & $0.53 \pm 0.03^{+++}$ \\
Urea (mg/dl) & $36.7 \pm 1.63$ & $47.99 \pm 1.53^{* * *}$ & $35.58 \pm 1.06^{+++}$ & $38.75 \pm 1.31^{+++}$ \\
\hline
\end{tabular}

The data are expressed in mean \pm SEM ( $n=10$ animals for each four groups). ${ }^{*} p<0.05,{ }^{* *} p<0.01,{ }^{* * *} p<0.001$ compared with group control, ${ }^{+} \mathrm{p}<0.05,{ }^{++} \mathrm{p}<0.01,{ }^{+++} \mathrm{p}<0.001$ compared with group EG.
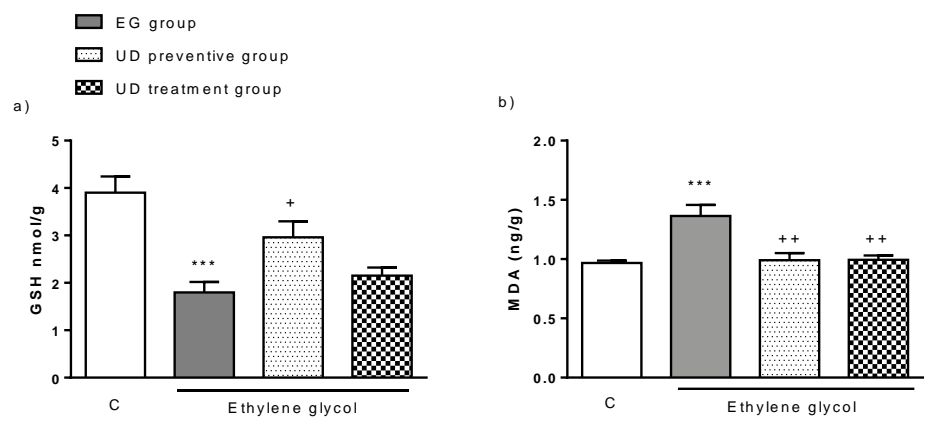

Figure 1. The level of GSH and MDA in kidney tissues. Values are expressed in mean \pm SEM ( $\mathrm{n}=10$ animals for each four groups). One-way ANOVA was carried out followed by post hoc Tukey multiple comparison test. ${ }^{* *} \mathrm{p}<0.001$, in comparison with control group; ${ }^{+} \mathrm{p}<0.05,{ }^{++} \mathrm{p}<0.01$, in comparison with EG group. GSH; Glutathione, MDA; Malondialdehyde.

\subsubsection{Effect of UD treatments on Caspase-3 activity and 8-OHdG}

When exposure to EG, there was significant elevation in kidney tissue apoptotic marker, caspase-3, and oxidative DNA damage marker, $8-\mathrm{OHdG},(\mathrm{p}<0.001)$ when compared with the control group. In UD preventive group, 8-OHdG were tended to decrease, however, in therapeutic UD group, 8-OHdG levels were decreased significantly when compared to EG group $(p<0.01)$. Similarly, UD pretreatment and treatment exhibited significant reduction in caspase- 3 activity in kidney tissues compared to the EG group $(\mathrm{p}<0.05, \mathrm{p}<0.01$, respectively) (Figure 2).

\subsubsection{Effect of UD treatments on NAG activity and TNF-a levels}

$\mathrm{N}$-acetyl- $\beta$-glucosaminidase (NAG) activity in the kidney of the EG group increased significantly ( $p$ $<0.05)$ compared to the control group. Although not significantly, UD pretreatment decreased the activity while in therapeutic UD group decrease in NAG activity was found to be significant when compared to EG group ( $p<0.05)$. As a result of EG exposure, TNF- $\alpha$ levels increased $(p<0.05, p<0.001$, respectively) compared with the control group. UD treatment caused to fall in TNF-a significantly (Figure 3).

\subsection{Histological results}

The normal renal tubule, glomerular structure and regular interstitial area in the cortex and medulla of the control group were observed. We observed that the tubular damage with dilatation, desquamation and degeneration are revealed in the EG-treated group. In addition to these findings, interstitial edema, congestion, 
tubular crystal and hyaline deposition were also observed. In the treatment and preventive groups tubular damage, dilatation and congestion were reduced.

$$
\begin{aligned}
& \square \text { EG group } \\
& \text { UD preventive group } \\
& \text { U UD treatment group }
\end{aligned}
$$
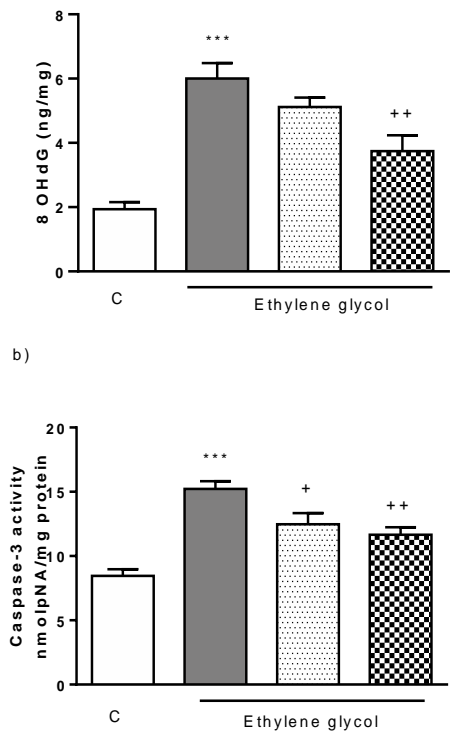

Figure 2. The level of 8-OHdG, caspase-3 in kidney tissues. Values are expressed in mean $\pm \mathrm{SEM}(\mathrm{n}=10$ animals for each four groups). One-way ANOVA was carried out followed by post hoc Tukey multiple comparison test. ${ }^{* *} \mathrm{p}<0.01,{ }^{* * *} \mathrm{p}<0.001$, in comparison with control group; ${ }^{+} \mathrm{p}<0.05,{ }^{++} \mathrm{p}<0.01$, in comparison with EG group.

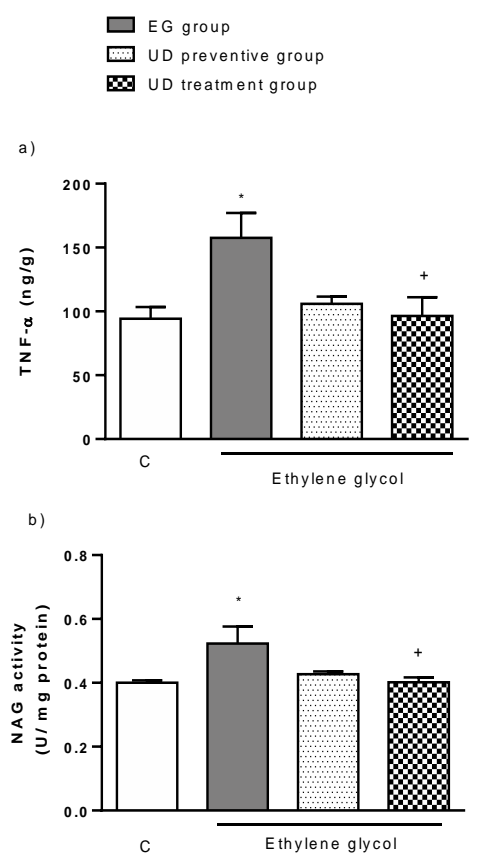

Figure 3. The level of TNF- $a(a)$ and NAG (b) in kidney tissue. Values are expressed in Mean \pm SEM ( $n=10$ animals for each four groups). One-way ANOVA was carried out followed by post hoc Tukey multiple comparison test. ${ }^{*} \mathrm{p}<0.05,{ }^{* * *} \mathrm{p}<0.001$, in comparison with control group; ${ }^{+} \mathrm{p}<0.05$, in comparison with EG group. NAG; N-Acetyl- $\beta$-glucosaminidase, TNF- $\alpha$; Tumor necrosis factor- $a$. 

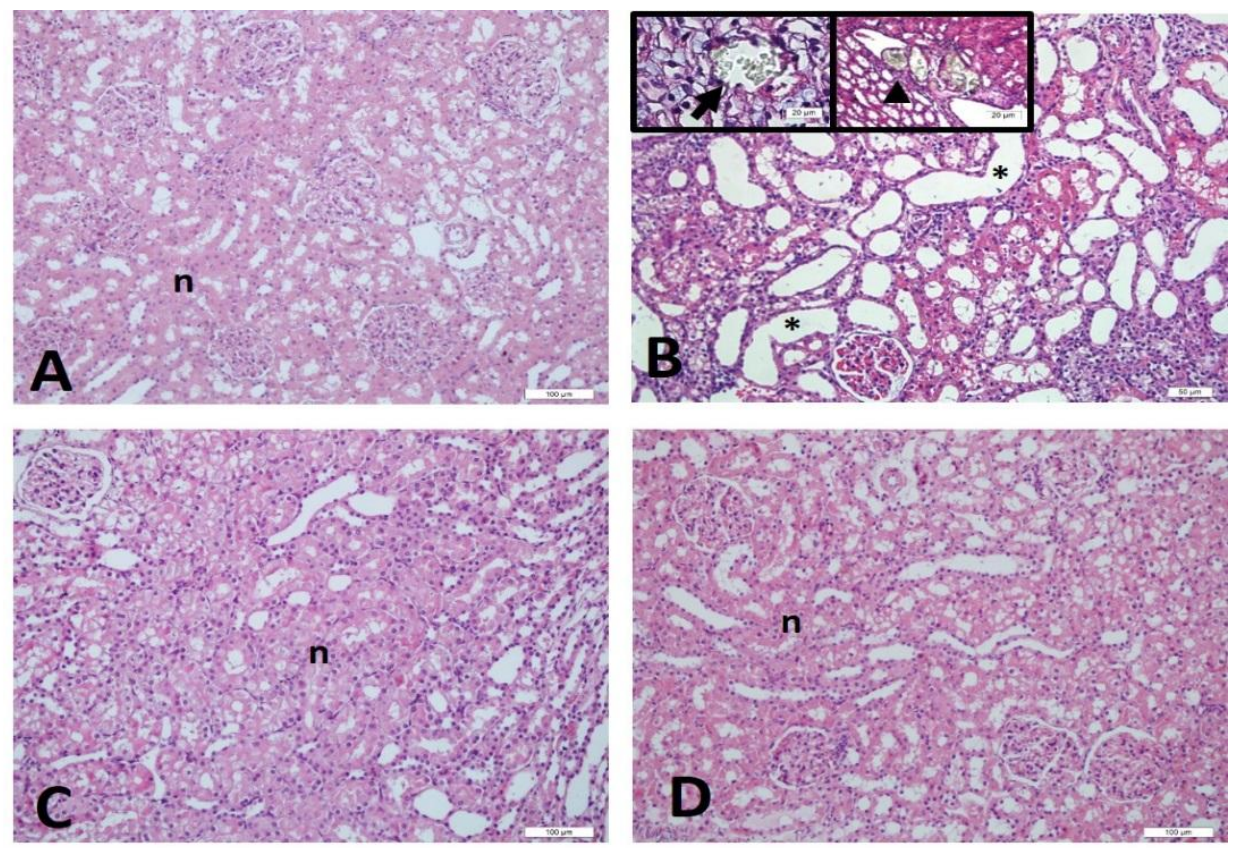

Figure 4. Representative light micrographs of kidney tissue in the experimental groups. A, control group normal tubules (n) in the kidney cortex. B, EG group rats with lots of birefringent crystals $\left({ }^{*}\right)$, desquamation, dilatation (*) and degeneration, fed with $75 \%$ EG. Normal cortex tubules and glomerulus in the C, UD Preventive group and D, UD Therapeutic group. H\&E staining Magnification, X 20, inset X 40.

\subsection{Immunohistochemical analyses}

\subsubsection{Immunohistochemical analyses of collagen 1}

Collagen I are detected by immunohistochemistry staining in the tubule epithelial cells exposed to the tubular basement membrane and interstitial space in the control group. This immunoreactivity of the Collagen I was similarly observed in the treatment and preventive groups. The dense Collagen I staining cells were mainly presented in the basement membrane in the EG group in comparison with others.

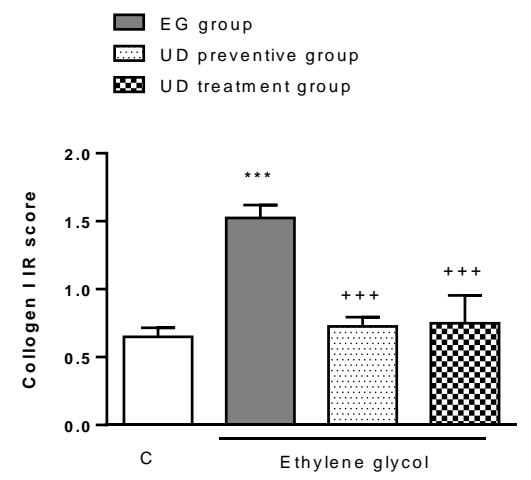

Figure 5. Collagen I comparison of experimental groups. ${ }^{* * *}$ p $<0.001$ compared with control group, +++ : $\mathrm{p}<0.001$ compared with EG group.

\subsubsection{Immunohistochemical analyses of KIM-1}

While there was no KIM-1 positive staining in renal tubules in the control group, the pale KIM-1 immuno-staining was observed in the pretreatment and treatment groups. In the EG group, intense KIM-1 immuno-staining was found especially in dilated tubules. The increased staining when compared with the control group was also supported with the semi-quantitative score $(\mathrm{p}<0.001)$. 

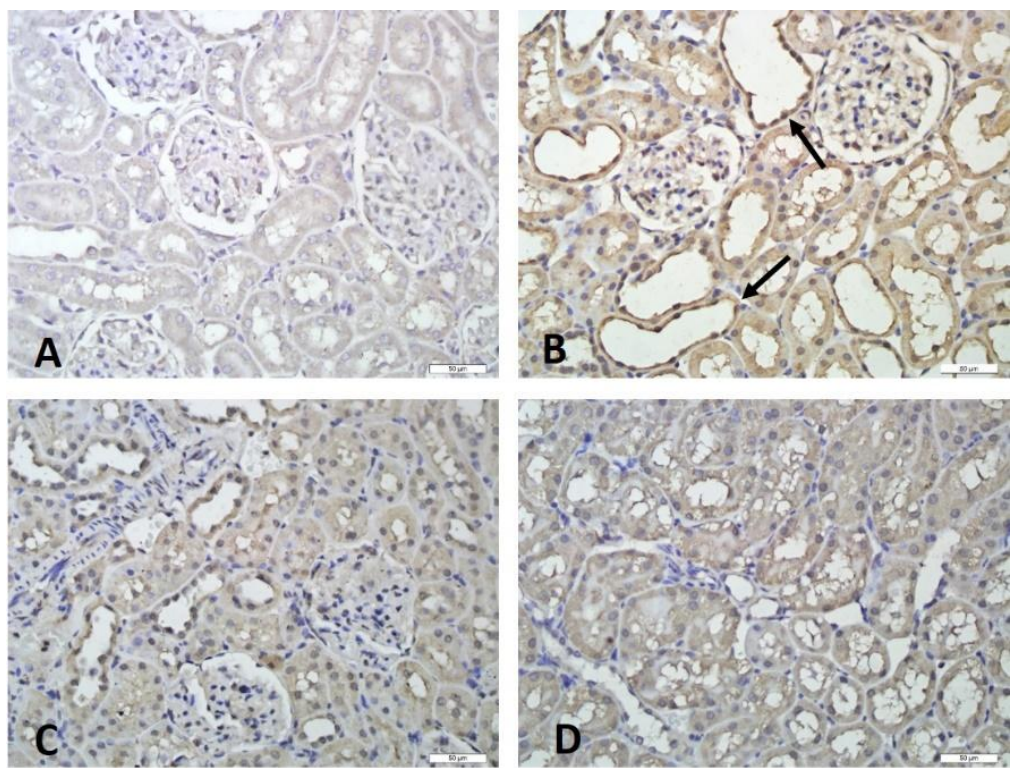

Figure 6. Representative light micrographs of Collagen I -stained of kidney tissue in the experimental groups A, Control B, Staining of the tubular basement membrane $(\leftarrow)$ Light staining C, UD Preventive group and D, UD Therapeutic group. Magnification, X 20.

$$
\begin{aligned}
& \square \text { EG group } \\
& \text { UD preventive group } \\
& \mathbf{\infty} \text { UD treatment group }
\end{aligned}
$$

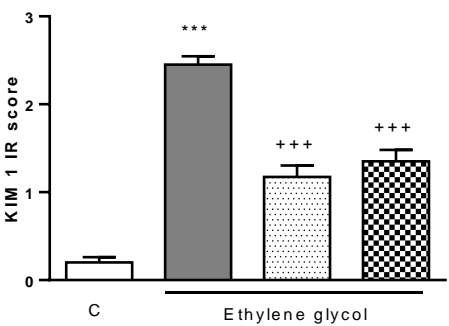

Figure 7. KIM 1 IR comparison of experimental groups. ***: $p<0.001$ compared with control group, +++ : $\mathrm{p}<0.001$ compared with EG group.
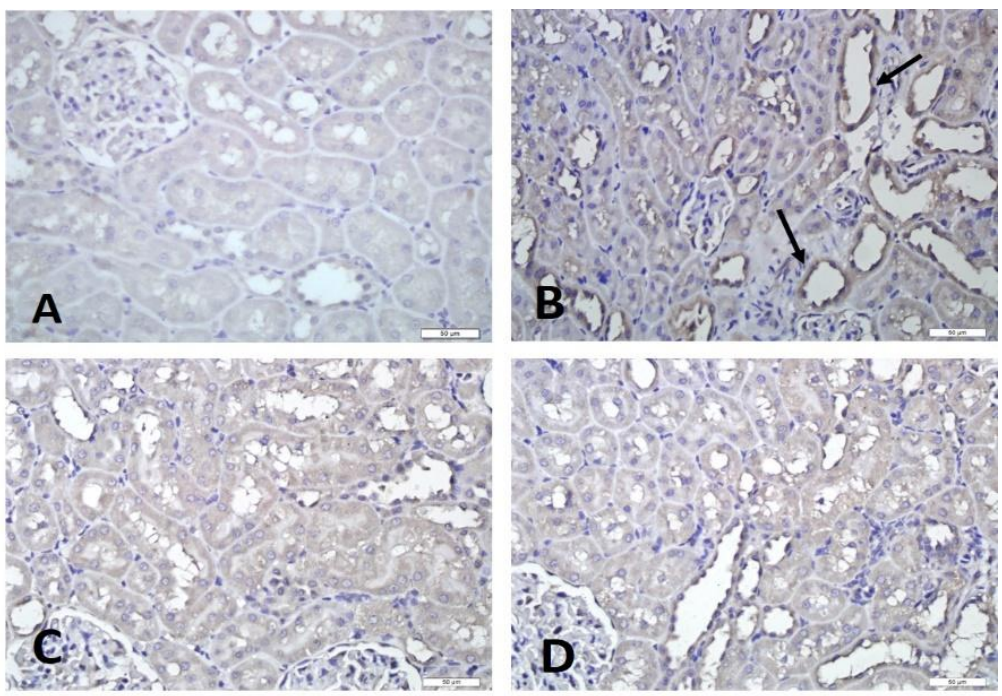

Figure 8. Representative light micrographs of KIM-I -stained of kidney tissue in the experimental groups A, Control B, EG group, showing large distended tubule and there is heavy expression in the tubular cells $(\leftarrow)$ Light staining C, UD Preventive group and D, UD Therapeutic group. Magnification, X 40. 


\subsubsection{Immunohistochemical analyses of $O P N$}

Osteopontin positive-staining of the renal tubules in the control, treatment and pretreatment groups was observed to be pale. In the EG group, we observed an intense staining in the damaged tubules. That intensity of the immuno-staining increased significantly $(p<0.001)$ when compared with the control group.

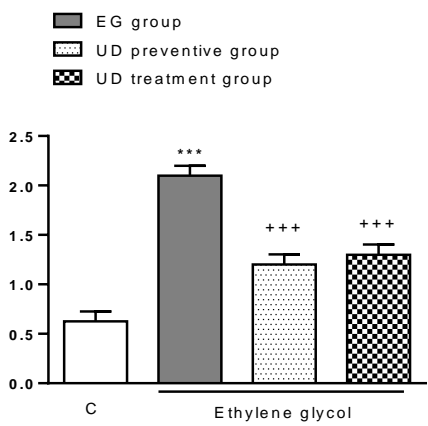

Figure 9. OPN comparison of experimental groups. ${ }^{* *}:$ p $<0.001$ compared with control group, ${ }^{+++:} \mathrm{p}<0.001$ compared with EG group.
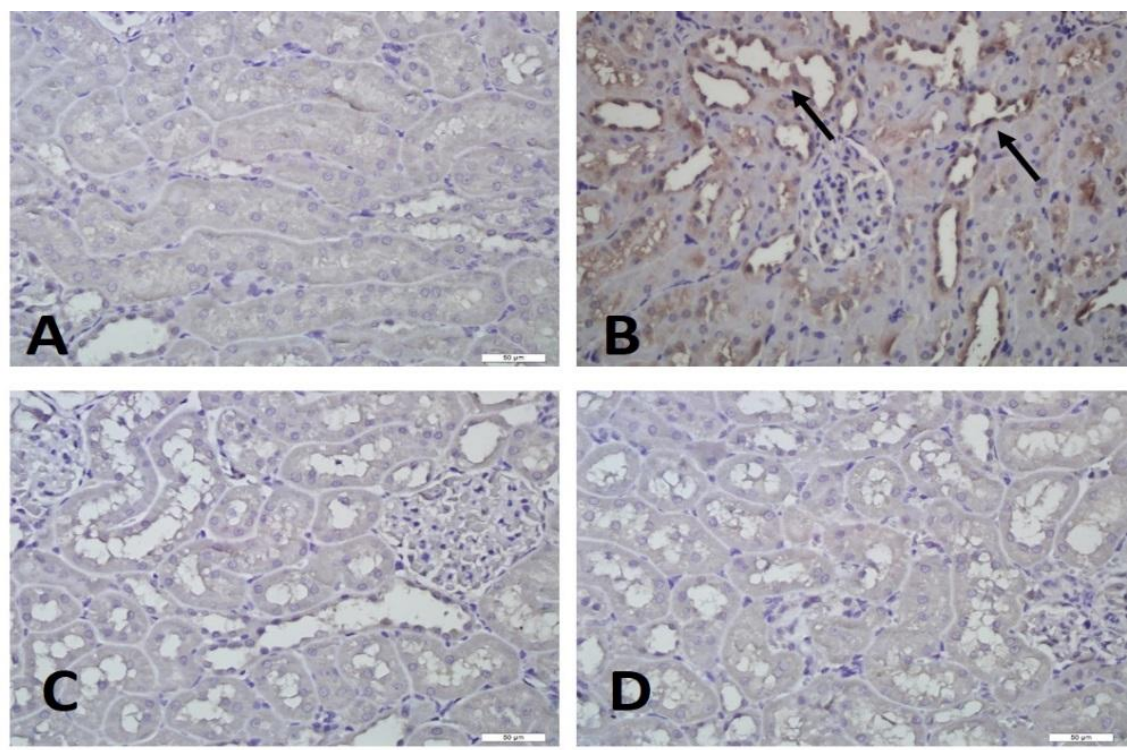

Figure 10. Representative light micrographs of OPN - stained of kidney tissue in the experimental groups A, Control B, EG group, showing strong staining of renal tubular epithelial cells shown by black arrows $(\longleftarrow)$. Showing light staining of the tubular epithelial cells, C, UD Preventive group and D, UD Therapeutic group. Magnification, X 20

\section{DISCUSSION}

Stone formation have several underlying processes, including nucleation, crystal growth, aggregation and retention. Administration of EG to rats induce formation of mainly $\mathrm{CaOx}$ stones. EG administration leading to increase in oxalate excretion causes hyperoxaluria [13]. Thereby, EG-induced rat model of kidney stone is described as one of the most appropriate experimental models to assess the possible antiurolithiatic effects of various medicines and herbs. The high recurrence rate of $\mathrm{CaOx}$ nephrolithiasis impairs the quality of life. Unfortunately, despite significant advances in medical therapy, there is no gratifying drug to prevent kidney stone formation [14]. So, there is a need to go beyond the current standard of care.

Previous studies displayed that various plant extracts have antiurolithiatic effects. In this regard, herbal medicines can be promising cure of new remedies of kidney stone [15]. Traditionally use of different parts of the UD has been reported. The utilization of UD has a long history for arterial hypertension in folk medicine in Morocco [16]. Similarly, in traditional Austrian medicine, tea or fresh leaves are used for kidney, urinary tract, gastrointestinal tract, and locomotor disorders. Again, the leaves of UD is used for rheumatism as a folk 
remedy [17]. Kadan et al. in 2013 found that UD therapy induced GLUT4 translocation in the in vitro muscle cells [18]. Patel et al. is showed that UD extract ameliorate depression like behavior and cognitive dysfunction in diabetic-induced model [19]. Recently, Peng Li et al. 2014 reported that treatment with the methanolic extract of Urtica dioica showed dose dependent curative effect on $\mathrm{CaOx}$ renal stone formation. UD could be a hopeful candidate for the treatment of nephrolithiasis [12]. However, its antiurolithiatic mechanism of effect was not enlightened. In accordance with this information, we purposed to research the antiurolithiatic mechanism of effect of UD. In this study, we demonstrated this antiurolithiatic effect once more and also evaluated several parameters for explaining the mechanism of action of UD and compared therapeutic and preventive effects of UD in EG-induced kidney stone model.

It has been showed that oxalate has a significant role in formation of kidney stone and has almost 15fold more effect than calcium [13]. In our study, the EG group showed a significant decrease in Ca and citrate excretion and increase oxalate excretion which show increased $\mathrm{CaOx}$ supersaturation. Ultimately this $\mathrm{CaOx}$ supersaturation results in stone formation. Since hyperoxaluria is one of the common results in $\mathrm{CaOx}$ urolithiasis that leads kidney stone disease, reduction in Ox level should be the therapeutic target [20]. In accordance with this hypothesis, in our study we observed that UD treatment decreased urinary oxalate levels, while urinary calcium and citrate levels were found to be increased. This is the first report on the effect of ethanol extract of Urtica dioica leaves for the preventive treatment of CaOx kidney stones.

Urinary obstruction owing to massive stones or crystals cause declined glomerular filtration, leading to gathering of nitrogenous contaminants such as creatinine and uric acid in blood [21,22]. The present study is in accordance with this information and showed that EG exposure increased serum levels of creatinine and uric acid. Therefore, preventive and therapeutic effects of UD treatment decreased the serum levels of creatinine and uric acid levels, which contribute to its curative efficacy in impaired kidney function.

We showed that MDA levels were significantly higher and GSH levels were lower in the kidney of the EG group. UD treatment produced a significant decrease in MDA and increase in GSH as markers of oxidative stress. Ashok and coworkers have shown that MDA concentrations were elevated and GSH concentrations were decreased in EG-given groups as a result of hyperoxaluria. An antioxidant Mimusops elengi extract administration to the rats with hyperoxaluri reduced significantly MDA levels and increased GSH levels [23]. Tugcu and coworkers have found that pomegranate juice (antioxidant) treatment decreased MDA levels and elevated GSH levels [24]. The results of these studies are similar to our findings and reveal that the protective effect of UD against oxidative changes induced by EG with both regime treatments.

Caspase-3 is an important mediator of programmed cell death [25]. Zhai et al. found that an increase of the caspase-3 activition, leading to apoptosis in EG-induced rats [26]. Consistent with the results of previous reports, we found that the caspase-3 activity is increased in kidney tissue in the EG group. This result indicate that the mitochondrial apoptotic pathway is also activated in the kidney tissue during forming stone. On the contrary, treatment with UD for 4 weeks almost reversed back the caspase- 3 activity indicating the potential inhibitory role of UD against programmed cell death.

8-OH-dG levels and NAG activity, were used as an important biomarker for oxidative DNA damage and tubular injury, respectively. There is a positive correlation between 8-OhdG and tubular damage, since urinary excretion of NAG was found to be increased [27]. It is the first time Boonla et al. in 2007 reported that increased urinary 8-OHdG levels in patient with stone. They also found that urinary NAG activity was increased, showing that positively linked with 8-OHdG. This research revealed that elevated tubular damage was found to be related oxidative stress [28]. Similarly, in our study, we observed that NAG and 8- OHdG in kidney tissues were increased in EG group compared with control group. UD administration ameliorated these parameters compared with EG group. It can be said that UD administration ameliorates the increase of oxidative stress, indicated by elevated 8-OHdG levels, thus repair the renal tubular damage.

Elevation of inflammatory biomarker such as TNF-a causes tissue inflammation of varying degrees in kidney stone. Enhanced level of this biomarker in serum clearly indicates an inflammatory condition [27]. Consistent with that, EG rats exhibited increased level on TNF-a. However, oral UD administration reduced the level of TNF-a, thus, UD is capable to ameliorate the inflammatory status in rats with nephrolithiasis.

Tubular degeneration, dilatation, degeneration, desquamation, interstitial edema, congestion, and mononuclear cell increase were evaluated and scored semi-quantitatively in our histological specimens. The changes we found were reported in similar studies [29,30,31]. When the EG group was compared with the control group, it was observed that the histological damage parameters increased significantly and these values approached the control values in both UD treatment and UD pretreatment group. 
Molecules usually involved in inflammatory pathways such as OPN and collagen, may be early and local participants of inflammation in interstitial plaques [32,33,34]. Collagen is part of interstitial CaP deposits and it has been reported by previous studies that it can play an essential role in the development of the disease. Collagen is stored during fibrosis. Joshi et al, observed the increase of Collagen I in tubular damage caused by crystal deposition and hyperoxaluria, the increase in the expression of collagen 1 in the renal tubular membrane and interstitial area after the exposure of 1\% EG. [29,35]. In our study, similar to previous studies, it was found that Collagen I immunoreactivity was significantly increased compared to control group, whereas treatment and pretreatment with UD significantly reduced this immunoreactivity compared to control group.

KIM-1 is a marker of acute or chronic tubulointerstitial damage [36]. In an animal study on the efficacy of KIM-1 as an early diagnostic biomarker for acute kidney injury, urinary KIM-1 levels have been shown to be five-fold higher without a significant decrease in creatinine levels or an increase in proteinuria [37]. In our study, we used the KIM-1 immunohistochemistry marker to determine tubular damage. In previous studies, an increase in KIM-1 immunoreactivity has been reported semi-quantitatively in the rat kidney tissue after a 1-week exposure to 1\% EG [29]. Similar to these studies, EG group showed intense KIM-1 immunostaining compared to the control group but showed a significant reduction in the treatment and pretreatment groups of UD in our study [38]. Many studies have shown that OPN expression is regulated as a protective response to crystal formation and high phosphate levels [39,40,41]. In the study of Tsuji et al. with human urine, kidney stone patients showed a significant decrease in urinary OPN levels compared to non-patient volunteer participants. In their study in 2017, Joshi et al. examined OPN expression on the 14th and 28th days and showed a significant increase in OPN expression on the 28th day, which correlated with crystalluria. In another study with rats treated with $1 \% \mathrm{EG}$, pioglitazone, a peroxisome proliferating activated receptor agonist, was used as a therapeutic agent and immunohistological examinations showed a decrease in OPN expression by pioglitazone treatment [41]. Similar to previous studies, we found a significant decrease in OPN expression in both the UD treatment group and the UD pretreatment group despite significant increase in osteopontin expression in the EG group immunohistochemically.

Phenolic compounds may prevent the lipid peroxidation-induced renal damage caused by CaOx crystal deposition in the kidney. It was also reported that hypoglccemic, antihyperlipidemic, anti-inflammatory, and antioxidant activities of chlorogenic acid may improve the renal function in diabetic nephropathy [42]. Recent studies have shown that the flavonoids could effectively inhibit the formation of $\mathrm{CaOx}$ stones in vitro and in vivo, correlating with their diuretic, antioxidant, anti-inflammatory, antibacterial properties and other protective effects [43]. Pinelli et al. was reported that the leaves of two Urtica dioica samples, cultivated and wild, contained large amounts of chlorogenic and 2-O-caffeoylmalic acid, which represent 71.5 and $76.5 \%$ of total phenolics, respectively [44]. The flavonoid compounds such as kaempferol, etc., and phenolic acids, such as chlorogenic acid, etc., found in the UD may be the compounds responsible for the antiurolithiatic activity of the UD.

\section{CONCLUSION}

The results of the present study indicate that Urtica dioica extract, a strong antioxidant, has the potential to prevent kidney stone formation due to crystal formation and aggregation, when used especially as a therapeutic agent. In the light of these findings, we suggest that UD is beneficial in kidney stone treatment and the effects may come from its antioxidant properties. Further studies are needed to clarify the mechanism of action of UD in preventing kidney stone formation.

\section{MATERIALS AND METHODS}

40 Sprague-Dawley rats (250-300 g) were supplied by Marmara University Animal Center and were housed in an air-conditioned room at $25^{\circ} \mathrm{C}$, humidity at 55-65\% under with 12 hours light-dark cycles. All the experimental protocols were approved by Marmara University Animal Care and Use Committee.

\subsection{Plant material and preparation of extract UD}

Urtica dioica leaves were collected in 2017 from Sakarya, Turkey (Adapazarı region) and identified by Dr. Ahmet Dogan, a botanist in the School of Pharmacy, University of Marmara. Voucher specimens were deposited at the Herbarium of the School of Pharmacy, Marmara University (MARE No: 22297). Dried and powdered Urtica dioica leaves ( $90 \mathrm{~g} \times 17$ times) were extracted with $96 \%$ of ethanol in a Soxhlet apparatus. Then, 
the solvent of extract evaporated under reduced pressure at $40^{\circ} \mathrm{C}$ and obtained extract was dried under the vacuum. The yield of extract was found to be $14.64 \%$. Extract was stored at $4^{\circ} \mathrm{C}$ until analysis.

\subsubsection{In vitro antioxidant and anti-inflammatory activity}

DPPH (2,2-diphenyl-1-picrylhydrazyl) and ABTS (2,2-azino-bis-3-ethylbenzothiazoline-6- sulfonic acid) radical scavenging activity of extract were measured according to Zou et al. [45]. The anti-inflammatory activity was evaluated as described by Phosrithong \& Nuchtavorn with slight modifications described by Yildirım et al. [46,47].

\subsubsection{Determination of total phenolic content of $U D$}

Total phenolic content of the extract was measured as described by Gao et al. with slight modifications described by Yıldırım et al. [47,48].

\subsection{In vivo studies}

40 Sprague-Dawley rats (250-300 g) were supplied by Marmara University Animal Center and were housed in an air-conditioned room at $25^{\circ} \mathrm{C}$ under with 12 hours light-dark cycles. All the experimental protocols were approved by Marmara University Animal Care and Use Committee (88.2017.mar).

The rats were divided into 4 groups, each containing 10 rats. The control group was given normal drinking water for 8 weeks and was administered vehicle by oral gavage. EG group received $0.75 \%$ EG in their drinking water during the study. Preventive group received $0.75 \%$ EG in their drinking water and ethanol extract of Urtica dioica at $700 \mathrm{mg} / \mathrm{kg}$ via oral gavage for 8 weeks. Therapeutic group received $0.75 \% \mathrm{EG}$ in their drinking water for 8 weeks while ethanol extract of Urtica dioica at $700 \mathrm{mg} / \mathrm{kg}$ was given to these rats from the 4 th week until the end of the study by oral gavage.

After the experimental period, 24-hour urine was collected and then all rats were decapitated to obtain blood and kidney tissues.

\subsection{Biochemical parameters}

\subsubsection{Analysis of urine and blood samples}

At the end of the $8^{\text {th }}$ week, all the animals were housed in individual metabolic cages, and a 24-h urine sample was collected before sacrification. Urinary calcium, oxalate, citrate, phosphate levels were measured with commercial kits from Colorimetric Abbott BNSRL (Italy). In blood samples creatinine and urea were analyzed Abbott (USA) reagents.

\subsubsection{Analaysis of kidney samples}

After the animals were sacrificed; both kidneys were removed from each animals and washed with cold $0.9 \% \mathrm{NaCl}$. The right kidney was minced with scissors and then homogenized in $0.9 \% \mathrm{NaCl}$ using a glass homogenizer. It was further centrifuged at $2000 \mathrm{rpm}$ for $10 \mathrm{~min}$ in a refrigerated centrifuge to remove cell debris. The supernatant was analyzed for malondialdehyde (MDA), glutathione (GSH), 8hydroxydeoxyguanosine (8-OHdG), tumor necrosis factor- $\alpha$ (TNF- $\alpha$ ) levels and N-acetyl- $\beta$-glucosaminidase (NAG) and caspase-3 activities using commercially available kits (Shanghai YL Biotech Co., Ltd.).

\subsection{Histopathological analysis}

\subsubsection{Histopathological analysis of kidney}

The left kidney was fixed in pre-formalin $(10 \%)$, embedded in paraffin, cut into 4 - $\mu \mathrm{m}$-thick sections, stained for histopathology (hematoxylin and eosin) and immunohistochemistry. All stained sections were evaluated using light microscope (Olympus BX51, Tokyo, Japan). Examination of histopathologic changes such as tubular degeneration-dilatation-desquamation, interstitial edema, congestion and tubular hyaline deposition was done.

\subsection{Immunohistochemical analysis}

Kidney tissues were fixed in formalin $(10 \%)$ to immunohistochemical analyses of collagen, osteopontin and kidney injury molecule-1 (KIM-1). $4 \mu \mathrm{m}$ paraffin sections were cut, mounted on slides, dewaxed in xylene, and kept in $96 \%$ alcohol. Endogenous enzyme activity was blocked by incubation with hydrogen peroxide for 20 minutes. After washing with PBS, the slides were incubated overnight with antibody for anti-collagen-1 (Novus, fold no: NBP2-29651 Rabbit Polyclonal Collagen I alpha 1 Antibody) and anti-KIM-1 (Novus, coat 
number: NBP2-46655 Rabbit Polyclonal TIM-1 / KIM-1 / HAVCR Antibody) and anti-osteopontin (Novus, fold no: NB600-1043, Rabbit Polyclonal Osteopontin / OPN Antibody), followed by biotinylated secondary antibodies and streptavidin-peroxidase conjugates (Histostain-plus Kit, Thermo Scientific, Germany) The detection step was performed by treatment with diaminobenzidine (ScyTek Laboratories Inc., Logan, UT, USA) and stained with hematoxylin. Immunoreactivity (ir) was evaluated semiquantitatively, none (0), mild intensity (1), moderate intensity (2) and intensive (3) [49].

\subsection{Statistical analysis}

The data were analysed using Graph Pad software. The result among the groups were analysed by oneway ANOVA followed by Tukey's multiple comparison tests. Statistical difference was considered significant at $\mathrm{p}<0.05$. Results were expressed as mean \pm Standard error of mean (SEM).

Acknowledgements: This study was supported by Marmara University Scientific Research Projects Commission with project number SAG-C-DRP-131217-0653.

Author contributions: Concept - R.K., G.Ş.; Design - R.K., B.E., G.Ş., Ş.Ç.; Supervision - R.K., G.Ş.; Resources - R.K., A.Ş., D.K., B.E., G.Ş; Materials - R.K., A.Ş., A.D., D.K., G.Ş.; Data Collection and/or Processing - R.K., D.K., B.E., G.Ş., A.D., P.E.; Analysis and/or Interpretation - R.K., B.E., P.E., T.E.Ş., G.Ş., Ş.Ç.; Literature Search - R.K., T.E.Ş., G.Ş.; Writing - R.K., G.Ş.; Critical Reviews - R.K., B.E., T.E.Ş., G.Ş., A.Ş., D.K., P.E., S..Ç., A.D.

Conflict of interest statement: The authors declare that they have no conflict of interest.

Ethics committee approval: All the experimental protocols were approved by Marmara University Animal Care and Use Committee (88.2017.mar).

\section{REFERENCES}

[1] Alelign T, Petros B. Kidney Stone Disease: An Update on Current Concepts. Adv Urol. 2018; 2018: 3068365. [CrossRef]

[2] Shah O, Assimos DG, Holmes RP. Genetic and dietary factors in urinary citrate excretion. J Endourol. 2005; 19: 177182. [CrossRef]

[3] Sakhaee K. Nephrolithiasis as a systemic disorder. Curr Opin Nephrol Hypertens. 2008; 17: 304-9. [CrossRef]

[4] Khan SR, Pearle MS, Robertson WG, Gambaro G, Canales BK, Doizi S, Traxer O, Tiselius HG. Kidney stones. Nat Rev Dis Primers. 2016; 25: 16008. [CrossRef]

[5] Yousefi Ghale-Salimi M, Eidi M, Ghaemi N, Khavari-Nejad RA. Inhibitory effects of taraxasterol and aqueous extract of Taraxacum officinale on calcium oxalate crystallization: in vitro study. Ren Fail. 2018; 40(1): 298-305. [CrossRef]

[6] Agawane SB, Gupta VS, Kulkarni MJ, Bhattacharya AK, Koratkar SS, Rao VK. Patho-physiological evaluation of Duranta erecta for the treatment of urolithiasis. J Ayurveda Integr Med. 2019; 10(1): 4-11. [CrossRef]

[7] Emamiyan MZ, Vaezi G, Tehranipour M, Shahrohkabadi K, Shiravi A. Preventive effects of the aqueous extract of Cichorium intybus L. flower on ethylene glycol-induced renal calculi in rats. Avicenna J Phytomed. 2018; 8(2): 170-178.

[8] Nirumand MC, Hajialyani M, Rahimi R, Farzaei MH, Zingue S, Nabavi SM, Bishayee A. Dietary Plants for the Prevention and Management of Kidney Stones: Preclinical and Clinical Evidence and Molecular Mechanisms. Int J Mol Sci. 2018; 19(3): 765. [CrossRef]

[9] Güner A, Türkiye Bitkileri Listesi (Damarlı bitkiler), firsth ed., Nezahat Gökyiğit Botanik Bahçesi Yayınları, Istanbul, Turkey 2012.

[10] Joshi BC, Mukhija M, Kalia AN. Pharmacognostical review of Urtica dioica L. Int J Green Pharmacy. 2014; 8(4): 201209.

[11] Salih NA. Effect of nettle (Urtica dioica) extract on gentamicin induced nephrotoxicity in male rabbits. Asian Pac J Trop Biomed. 2015; 5(9): 756-760. [CrossRef]

[12] Zhang H, Li N, Li K, Li P. Protective effect of Urtica dioica methanol extract against experimentally induced urinary calculi in rats. Mol Med Rep. 2014; 10(6): 3157-3162. [CrossRef]

[13] Karadi RV, Gadge NB, Alagawadi KR, Savadi RV. Effect of Moringa oleifera Lam. root-wood on ethylene glycol induced urolithiasis in rats. J Ethnopharmacol. 2006; 105(1-2): 306-311. [CrossRef]

[14] Lin WC, Lai MT, Chen HY, Ho CY, Man KM, Shen JL, Lee YJ, Tsai FJ, Chen YH, Chen WC. Protective effect of Flos carthami extract against ethylene glycol-induced urolithiasis in rats. Urol Res. 2012; 40(6): 655-661. [CrossRef] 
[15] Gupta S, Kanwar SS. Phyto-molecules for Kidney Stones Treatment and Management. Anal Biochem. $2018 ; 7: 4$. [CrossRef]

[16] Mekhfi H, El Haouari M, Legssyer A, Bnouham M, Aziz M, Atmani F, Remmal A, Ziyyat A. Platelet anti-aggregant property of some Moroccan medicinal plants. J Ethnopharmacol. 2004; 94(2-3): 317-322. [CrossRef]

[17] Vogl S, Picker P, Mihaly-Bison J, Fakhrudin N, Atanasov AG, Heiss EH, Wawrosch C, Reznicek G, Dirsch VM, Saukel J, Kopp B. Ethnopharmacological in vitro studies on Austria's folk medicine--an unexplored lore in vitro antiinflammatory activities of 71 Austrian traditional herbal drugs. J Ethnopharmacol. 2013; 149(3): 750-771. [CrossRef]

[18] Kadan S, Saad B, Sasson Y, Zaid H. In Vitro Evaluations of Cytotoxicity of Eight Antidiabetic Medicinal Plants and Their Effect on GLUT4 Translocation. Evid Based Complement Alternat Med. 2013; 2013: 549345. [CrossRef]

[19] Patel SS, Udayabanu M. Urtica dioica extract attenuates depressive like behavior and associative memory dysfunction in dexamethasone induced diabetic mice. Metab Brain Dis. 2014; 29(1): 121-130. [CrossRef]

[20] Khan SR. Animal models of kidney stone formation: an analysis. World J Urol. 1997; 15: 236e43 [CrossRef]

[21] Bouanani S, Henchiri C, Migianu-Griffoni E, Aouf N, Lecouvey M. Pharmacological and toxicological effects of Paronychia argentea in experimental calcium oxalate nephrolithiasis in rats. J Ethnopharmacol. 2010; 129(1):38-45. [CrossRef]

[22] El Menyiy N, Al Waili N, Bakour M, Al-Waili H, Lyoussi B. Protective Effect of Propolis in Proteinuria, Crystaluria, Nephrotoxicity and Hepatotoxicity Induced by Ethylene Glycol Ingestion. Arch Med Res. 2016; 47(7): 526-534. [CrossRef]

[23] Ashok P, Koti BC, Vishwanathswamy AH. Antiurolithiatic and antioxidant activity of Mimusops elengi on ethylene glycol-induced urolithiasis in rats. Indian J Pharmacol. 2010; 42(6): 380-383. [CrossRef]

[24] Tugcu V1, Kemahli E, Ozbek E, Arinci YV, Uhri M, Erturkuner P, Metin G, Seckin I, Karaca C, Ipekoglu N, Altug T, Cekmen MB, Tasci AI. Protective effect of a potent antioxidant, potent antioxidant, pomegranate juice, in the kidney of rats with nephrolithiasis induced by ethylene glycol. J Endourol. 2008; 22: 2723-2731. [CrossRef]

[25] Tunçdemir M, Demirkesen O, Oztürk M, Atukeren P, Gümüştaş MK, Turan T. Antiapoptotic effect of angiotensin-II type-1 receptor blockade in renal tubular cells of hyperoxaluric rats. Urol Res. 2010; 38(2): 71-80. [CrossRef]

[26] Zhai W, Zheng J, Yao X, Peng B, Liu M, Huang J, Wang G, Xu Y. Catechin prevents the calcium oxalate monohydrate induced renal calcium crystallization in NRK-52E cells and the ethylene glycol induced renal stone formation in rat. BMC Complement Altern Med. 2013; 13: 228. [CrossRef]

[27] Khan SR. Reactive oxygen species, inflammation and calcium oxalate nephrolithiasis. Transl Androl Urol. 2014; 3(3): 256-276. [CrossRef]

[28] Boonla C, Wunsuwan R, Tungsanga K, Tosukhowong P. Urinary 8-hydroxydeoxyguanosine is elevated in patients with nephrolithiasis. Urol Res. 2007; 35(4): 185-191. [CrossRef]

[29] Joshi S, Wang W, Khan SR. Transcriptional study of hyperoxaluria and calcium oxalate nephrolithiasis in male rats: Inflammatory changes are mainly associated with crystal deposition. PLoS One. 2017; 12(11): e0185009. [CrossRef]

[30] Chen W, Liu WR, Hou JB, Ding JR, Peng ZJ, Gao SY, Dong X, Ma JH, Lin QS, Lu JR, Guo ZY. Metabolomic analysis reveals a protective effect of Fu-Fang-Jin-Qian-Chao herbal granules on oxalate-induced kidney injury. Biosci Rep. 2019; 22; 39(2). [CrossRef]

[31] Sayhan MB, Kanter M, Oguz S, Erboga M. Protective effect of Urtica dioica L. on renal ischemia/reperfusion injury in rat. J Mol Histol. 2012; 43(6): 691-698. [CrossRef]

[32] Habbig S, Beck BB, Hoppe B. Nephrocalcinosis and urolithiasis in children. Kidney Int. 2011; 80: 1278-1291. [CrossRef]

[33] Pak CY, Adams-Huet B, Poindexter JR, Pearle MS, Peterson RD, Moe OW. Relative effect of urinary calcium and oxalate on saturation of calcium oxalate Rapid Communication. Kidney Int. 2004; 66(5): 2032-2037. [CrossRef]

[34] Asplin J, DeGanello S, Nakagawa YN, Coe FL. Evidence that nephrocalcin and urine inhibit nucleation of calcium oxalate monohydrate crystals. Am J Physiol. 1991; 261(5 Pt 2): F824-30. [CrossRef]

[35] Macneil F, Bariol S. Urinary stone disease- assessment and management. Aust Fam Physician. 2011; 40(10): $772-775$.

[36] Gauer S, Urbschat A, Gretz N, Hoffmann SC, Kränzlin B, Geiger H, Obermüller N. Kidney Injury Molecule-1 Is Specifically Expressed in Cystically-Transformed Proximal Tubules of the PKD/Mhm (cy/+) Rat Model of Polycystic Kidney Disease. Int J Mol Sci. 2016; 17(6). pii: E802. [CrossRef] 
[37] Vaidya VS1, Ramirez V, Ichimura T, Bobadilla NA, Bonventre JV. Urinary kidney injury molecule-1: a sensitive quantitative biomarker for early detection of kidney tubular injury. Am J Physiol Renal Physiol. 2006; 290(2): F51729. [CrossRef]

[38] Mohamaden W, Wang H, Guan H, Meng X, Li J. Immunohistochemical localization and mRNA quantification of osteopontin and Tamm-Horsfall protein in canine renal tissue after potassium oxalate injection. BMC Vet Res. 2014; 17; 10: 70. [CrossRef]

[39] Hirota S, Imakita M, Kohri K, Ito A, Morii E, Adachi S, Kim HM, Kitamura Y, Yutani C, Nomura S. Expression of Osteopontin Messenger RNA by Macrophages in Atherosclerotic Plaques, A Possible Association with Calcification. Am J Pathol. 1993; 143(4):1003-1008. [CrossRef]

[40] Beck GR Jr, Zerler B, Moran E. Phosphate is a specific signal for induction of osteopontin gene expression. Proc Natl Acad Sci U S A. 2000; 97(15): 8352-8357.

[41] Taguchi K, Okada A, Yasui T, Kobayashi T, Ando R, Tozawa K, Kohri K. Pioglitazone, a Peroxisome Proliferator Activated Receptor y Agonist, Decreases Renal Crystal Deposition, Oxidative Stress and Inflammation in Hyperoxaluric Rats. J Urol. 2012; 188(3): 1002-1011. [CrossRef]

[42] Ilhan M, Ergene B, Süntar I, Ozbilgin S, Saltan Çitoğlu G, Demirel MA, Keleş H, Altun L, Küpeli Akkol E. Preclinical Evaluation of Antiurolithiatic Activity of Viburnum opulus L. on Sodium Oxalate-Induced Urolithiasis Rat Model. Evid Based Complement Alternat Med. 2014; Article ID: 578103. [CrossRef]

[43] Zeng X, Xi Y, Jiang W. Protective roles of flavonoids and flavonoid-rich plant extracts against urolithiasis. Crit Rev Food Sci Nutr. 2019; 59(13): 2125-2135. [CrossRef]

[44] Pinelli P, Ieri F, Vignolini P, Bacci L, Baronti S, Romani A. Extraction and HPLC Analysis of Phenolic Compounds in Leaves, Stalks, and Textile Fibers of Urtica dioica L. J Agric Food Chem. 2008; 56(19): 9127-32. [CrossRef]

[45] Zou YH, Liu WT, Zhang JX, Xiang DC. Triterpenoids from the bark of Dysoxylum hainanense and their antiinflammatory and radical scavenging activity. Fitoterapia. 2017; 121: 159-163. [CrossRef]

[46] Phosrithong N, Nuchtavorn N. Antioxidant and anti-inflammatory activites of Clerodendrum leaf extracts collected in Thailand. Eur J Integr Med. 2016; 3: 281-285. [CrossRef]

[47] Yıldırım A, Şen A, Doğan A, Bitiş L. Antioxidant and anti-inflammatory activity of capitula, leaf and stem extracts of Tanacetum cilicicum (Boiss.) Grierson. International Journal of Secondary Metabolite. 2019; 6: 211-222. [CrossRef]

[48] Gao X, Ohlander M, Jeppsson N, Björk L, Trajkovski V. Changes in antioxidant effects and their relationship to phytonutrients in fruits of Sea Buckthorn (Hippophae rhamnoides L.) during maturation. Journal of Agricultural and Food Chemistry. 2000; 48,1485-1490. [CrossRef]

[49] Koca U, Olguner ÇG, Ergür BU, Altekin E, Taşdöğen A, Duru S, Girgin P, Gündüz K, Cilaker Micılı S, Güzeldă̆ S, Akkuş M. The effects of dexmedetomidine on secondary acute lung and kidney injuries in the rat model of intraabdominal sepsis. ScientificWorldJournal. 2013; 2013:292687. [CrossRef] 